\title{
Oxidant balance in brain of rats receiving different compounds of selenium
}

\author{
Irena Musik • Małgorzata Kiełczykowska • \\ Joanna Kocot
}

Received: 9 April 2013/Accepted: 2 July 2013/Published online: 10 July 2013

(C) The Author(s) 2013. This article is published with open access at Springerlink.com

\begin{abstract}
The influence of two organic selenocompounds and sodium selenite on oxidant processes in rat brain tissue was investigated. The study was performed on male Wistar rats. The animals were divided into four groups: I-control; II-administered with sodium selenite; III-provided with selenoorganic compound A of chain structure 4-(o-tolyl-)-selenosemicarbazide of 2-chlorobenzoic acid and IVprovided with selenoorganic compound $\mathrm{B}$ of ring structure 3-(2-chlorobenzoylamino-)-2-(o-tolylimino-)-4-methyl-4-selenazoline. Rats were treated by stomach tube at a dose of $5 \times 10^{-4} \mathrm{mg}$ of selenium/g of b.w. once a day for a period of 10 days. In brain homogenates total antioxidant status (TAS), activities of superoxide dismutase (SOD) and glutathione peroxidase (GPx), concentrations of ascorbic acid (AA) and reduced glutathione (GSH) as well as concentration of malonyl dialdehyde (MDA) were determined. TAS was insignificantly diminished in all seleniumsupplemented groups versus control. SOD was not significantly influenced by administration of selenium. GPx was markedly decreased in group III versus control, whereas increased in group IV versus control and group III. Selenosemicarbazide depleted AA in well-marked way versus group II. GSH was significantly depressed in group III versus both control and
\end{abstract}

I. Musik · M. Kiełczykowska · J. Kocot ( $\square)$ Chair and Department of Medical Chemistry, Medical University of Lublin, Chodźki 4a, 20-093 Lublin, Poland e-mail: joanna.kocot@umlub.pl group II and diminished in group IV versus group II. MDA was significantly decreased in group III versus both control and group II, whereas in group IV increased versus group III. As selenazoline A did not decrease elements of antioxidant barrier and increased GPx activity, it seems to be a promising agent for future studies concerning its possible application as a selenium supplement.

Keywords Selenium - Brain · Antioxidant defence · Lipid peroxidation $\cdot$ Male rats
Abbreviations
TAS Total antioxidant status
SOD Superoxide dismutase
GPx Glutathione peroxidase
AA Ascorbic acid
MDA Malonyl dialdehyde
GSH Reduced glutathione

\section{Introduction}

Selenium is an essential trace element, necessary to correct organism's functions (Yan et al. 2013). Its deficit may result in severe disorders including cancer (Klarod et al. 2011), dermatic and mood disorders (Ingen-Housz-Oro et al. 2004; Sopjani et al. 2008), illnesses of alimentary tract (Skelton et al. 2006), as 
well as AIDS development after HIV-infection (Rayman 2000). Selenium is also suggested to be involved into functioning of cartilage (Yan et al. 2013). Numerous research studies precede our studies on safe and effective supplements (Combs 2005; Řezanka and Sigler 2008; Selamoglu Talas et al. 2009) using diverse substances both inorganic (sodium selenite or selenate) (Ivancic and Weiss 2001; Ayaz and Turan 2006; Uezono et al. 2006) and organic (Xia et al. 2004; Burk et al. 2006; Pawlas and Małecki 2007; Cui et al. 2008; Selamoglu Talas et al. 2009) as well as selenium-enriched natural products e.g.: malt (Liu et al. 2006), yeast (Burk et al. 2006), broccoli (Řezanka and Sigler 2008), but the question of the best form remains unsolved. The main difficulties result from the narrow range between therapeutic and toxic dose of selenium (Hawkes et al. 2008) as well as from the dependence of its bioavailability on the form of supplementation (Burk et al. 2006). Since selenium is considered to be an antioxidant, as a constituent of one of the main antioxidative enzymes-glutathione peroxidase (Ha and Smith 2009), many investigations have concerned relationships between selenium and oxidative balance in organisms (Ghodbane et al. 2011; Horky et al. 2012; Zhang et al. 2013). Ebselen, a ring selenoorganic compound of isoselenazole structure has been found to possess antioxidant properties although its negative effects have also been stated (Farina et al. 2004; Shi et al. 2006). An organoselenium compound has also been shown to exert protective effect against side effects of cisplatin by the affecting of pro- and antioxidative processes (Ghosh et al. 2013).

Selenium is widely distributed throughout the body, and its high level occurs in the brain (van Eersel et al.
2010). As an antioxidant or a main constituent of brain selenoproteins, it appears to be an important factor in maintaining of brain functions (Akbaraly et al. 2007). Associations between low selenium levels and a significantly greater incidence of depression and other negative mood states such as anxiety, confusion, and hostility (Rayman 2000) as well as cognitive impairment, Alzheimer's disease (van Eersel et al. 2010) or brain tumors (Chen and Berry 2003) have been reported. Researchers have indicated that neurological disorders are often associated with oxidative stress (Chauhan et al. 2004; Mariani et al. 2005) and selenium compounds may display antioxidant and neuroprotective properties (Akbaraly et al. 2007). Having regarded these findings the aim of the present study was to evaluate the influence of the two newly synthesized organic selenocompounds with that exerted by acknowledged inorganic supplement sodium selenite, which is still used in clinical practice (Pagmantidis et al. 2008; Schnabel et al. 2008; Savory et al. 2012) and as a supplement of animal food (Pavlović et al. 2010), on oxidant processes in rat brain tissue.

\section{Materials and methods}

\section{Chemicals}

Two selenoorganic compounds were synthesized in our chair: compound A (chain structure) 4-(o-tolyl-)selenosemicarbazide of 2-chlorobenzoic acid (Musik et al. 2002) and compound B (ring structure) 3-(2chlorobenzoylamino-)-2-(o-tolylimino-)-4-methyl-4selenazoline (Musik et al. 2009).

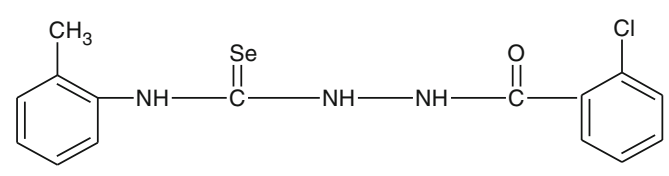

compound A

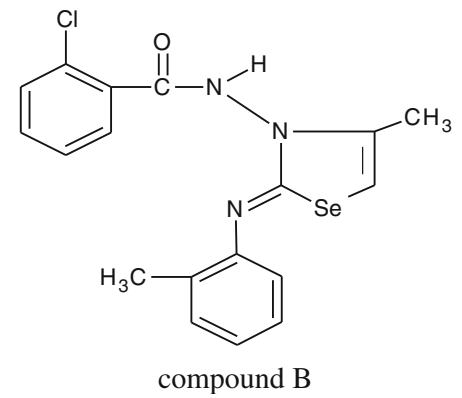


Animal experiment

The experiment was carried out on adolescent male Wistar rats. After 3 days of acclimatization the animals were randomly divided into four groups (ten animals each): group I (control with no selenium supplementation) - treated with saline, group IItreated with sodium selenite, group III-treated with 4-(o-tolyl-)-selenosemicarbazide of 2-chlorobenzoic acid, group IV-treated with 3-(2-chlorobenzoylamino-)-2-(o-tolylimino-)-4-methyl-4-selenazoline.

At the beginning of the experiment the weights of rats were included within a range of 110-150 g. Sodium selenite was given in form of water solution. Organic compounds A and B given to groups III and IV were suspended in the emulsion composed of oil, Arabic gum and water in the following proportion $2: 1: 1.5$. The administration was performed by stomach tube. Selenium compounds were given to rats at a dose of $5 \times 10^{-4} \mathrm{mg}$ of selenium/g of b.w. once a day for a period of 10 days. Body weights of animals were measured every day before selenium administration and the appropriate amount of selenium compound was calculated for each animal. The administered dose was relatively high but it was applied with the aim of studying toxicity of the new organoselenium compounds. It is difficult to foresee the toxic dose of a new compound as the bioavailability depends on its structure. The dose was chosen considering those applied by other authors which were included in the range from $1 \times 10^{-4} \mathrm{mg} / \mathrm{g}$ b.w. (Medeiros et al. 2012) to $19.7 \times$ $10^{-4} \mathrm{mg} / \mathrm{g}$ b.w. (Selamoglu Talas et al. 2008), mainly $2 \times 10^{-4}-3 \times 10^{-4} \mathrm{mg} / \mathrm{g}$ b.w. (El-Demerdash 2004; Agarval and Behari 2007; Naziroğlu et al. 2008; Akil et al. 2011a). Rats had free access to standard feed containing adequate level of selenium and drinking water. After the end of the experiment animals were sacrificed under pentothal narcosis.

The study was performed according to statutory bioethical standards and approved by I Local Ethical Commission of Medical University of Lublin, acceptance no. 65/AM/2004.

Preparing of brain samples and measurement of biochemical parameters

The samples of brain tissue were collected. Ten per cent $(\mathrm{w} / \mathrm{v})$ tissue homogenates were prepared in $0.1 \mathrm{~mol} / \mathrm{dm}^{3}$ Tris-HCl buffer, $\mathrm{pH}=7.4$. Supernatants were obtained by centrifugation at $5,000 \times g$ for $30 \mathrm{~min}$. The prepared material was stored at temperature $-18{ }^{\circ} \mathrm{C}$.

The following substances were determined in brain homogenates: total antioxidant status (TAS), activity of antioxidant enzymes - superoxide dismutase (SOD) and glutathione peroxidase (GPx), concentrations of non-enzymatic antioxidants-ascorbic acid (AA) and reduced glutathione (GSH) as well as concentration of lipid peroxidation marker-malonyl dialdehyde (MDA). TAS was measured using diagnostic kit produced by RANDOX and expressed in $\mathrm{mmol} / \mathrm{g}$ of protein. SOD and GPx activities were determined using diagnostic kits RANSOD and RANSEL produced by RANDOX and expressed in U/mg of protein and U/g of protein, respectively. GSH concentration was determined using BIOXYTECH ${ }^{\circledR}$ GSH- $400^{\mathrm{TM}}$ kit produced by OxisResearch ${ }^{\mathrm{TM}}$ and expressed in $\mu \mathrm{g}$ of $\mathrm{GSH} / \mathrm{mg}$ of protein. AA concentration was determined using modified Kyaw method (Rutkowski and Grzegorczyk 1998) and expressed in $\mu \mathrm{mol}$ of $\mathrm{AA} / \mathrm{g}$ of protein. MDA concentration was determined using Ledwożyw et al. (1986) method and expressed in nmol of MDA/mg of protein. Protein was measured using method of Bradford (1976). The assays were performed with use of spectrophotometer SPECORD M40 (Zeiss Jena).

\section{Statistical analysis}

Statistical analysis was performed using ANOVA test. Comparisons between control and selenium-supplemented groups as well as between selenium-supplemented groups were made using the Tukey's HSD test or Dunnett's T3 test. Values were considered significant with $p<0.05$. The choice of multiple comparisons test was dependent on evaluation of variance homogeneity in compared groups which was performed using Leven's test. In the event of homogeneous variances Tukey's method of honestly significant differences-HSD test was used, whereas when variances in groups were heterogeneous ( $p<0.05$ in Leven's test) T3 Dunnet's test (applicable in the case of heterogenous variances) was applied.

\section{Results}

TAS values were diminished in all selenium-supplemented groups, although this effect was not significant versus control with no selenium supplementation. 
Activities of antioxidant enzymes GPx and SOD were slightly increased versus control group in group II (inorganic sodium selenite). In group III (organic chain selenocompound) SOD was unchanged, whereas GPx was markedly decreased versus control. In group IV (organic ring selenocompound) both enzymes were increased versus control, although this effect was significant only in the case of GPx. In the case of GPx organic forms of selenium displayed insignificant differences when compared to inorganic selenite-in group III (chain compound) GPx was decreased versus group II, whereas in group IV (ring derivative) enhancement versus group II was observed. As concerns comparison between two studied organic forms-the significant increase in group IV versus group III was also observed.

Brain low-molecular antioxidants, AA and GSH were influenced by selenium-administration in different way, depending on the form of supplements. All the studied selenium compounds insignificantly decreased AA concentration versus control, whereas chain selenosemicarbazide depleted it in well-marked way versus group II (selenite). GSH was slightly enhanced in group II, significantly depressed in group III and practically unchanged in IV one in comparison with control. Both selenoorganic compounds significantly decreased GSH concentration in comparison with inorganic selenite group.

MDA brain concentration was unaltered in rats of group II (inorganic sodium selenite), significantly decreased in group III and insignificantly increased in group IV versus control. Organic forms of selenium showed differences compared to inorganic selenitein group III (chain compound) well-marked decrease in MDA versus group II, whereas in group IV (ring selenocompound) slight enhancement versus group II were observed. Moreover, there was the significant increase in MDA in group IV versus group III.

All the obtained results are presented in Fig. 1.

\section{Discussion}

Selenium is an essential element and its deficit may result in occurring of diverse disorders of organism functions. Selenium supplementation has been found to show beneficial effects in different pathological states. On the other hand supplementation must be carried out taking precautions as this element can cause negative effects, including disturbances of nervous system. Among other things, selenite was found to cause irregular neurons growth in fish embryos (Ma et al. 2012).

In the present study TAS was insignificantly decreased in selenium-administered rats. The lack of distinct relationships between selenium and TAS was also reported by Okuonghae et al. (2011) who found that in rats exposed to premium motor spirit fumes well-marked increase in plasma selenium was accompanied with no significant changes of TAS value. Another study also revealed no significant correlations between selenium supplementation and blood TAS (Savory et al. 2012). The decrease in TAS value observed in our study can hardly be connected with the changes of any other studied antioxidant. As distinct from TAS changes these alterations depended on the structure on the used selenocompound. It is possible that TAS decrease could be related with other substances of antioxidant properties. Among other things some selenoproteins (selenoprotein $\mathrm{P}$, thioredoxin reductases and methionine sulphoxide reductase B) were found to act as antioxidants (Hoffmann et al. 2007; Steibrenner and Sies 2013). Further researches including the influence of selenium supplementation on expression of these proteins might contribute to the clarification of this question. When considering reported opinions on selenium supplementation and our results (Herrmann et al. 2001; Feng et al. 2012), measuring TAS is more recommended than determining changings of individual antioxidants.

Antioxidative enzymes GPx and SOD were increased by inorganic selenium and selenoorganic ring compound, whereas the chain derivative caused their decrease versus control, although these effects were significant only in the case of GPx in groups III and IV (selenoorganic compounds). The outcomes of the present study concerning sodium selenite administration are confirmed by other authors' reports. Sodium selenite increased SOD and GPx activity in brain of cadmium-exposed as well as non-exposed suckling rats. The applied dose and period of treatment were comparable-0.632 mg selenium $/ \mathrm{kg}$ b.w. and 9 days, respectively (Lazarus et al. 2011) to those used in the present experiment. In mice treated with methylmercury GPx activity in cerebral cortex was decreased and co-administration of sodium selenite did not exert any influence, whereas in non-exposed animals increase in GPx was observed (Glaser et al. 
Fig. 1 Effect of selenium supplementation on oxidative parameters in brain of rats. Rats were randomly divided into four groups (10 animals each) and intragastrically treated with: saline (group I); sodium selenite (group II), 4-(o-tolyl-)selenosemicarbazide of 2-chlorobenzoic acid (group III) and 3-(2chlorobenzoylamino-)-2(o-tolylimino-)-4-methyl4-selenazoline (group IV). Data are means \pm SD. $* p<0.05 ; * * * p<0.001$ versus group I ${ }^{\mathrm{A}} p<0.05$; ${ }^{\mathrm{B}} p<0.01 ;{ }^{\mathrm{C}} p<0.001$ versus group II $\mathrm{X}_{p}<0.05$; ${ }^{\mathrm{Y}} p<0.01$; versus group III (H) Tukey's HSD test (D) T3 Dunnett's test
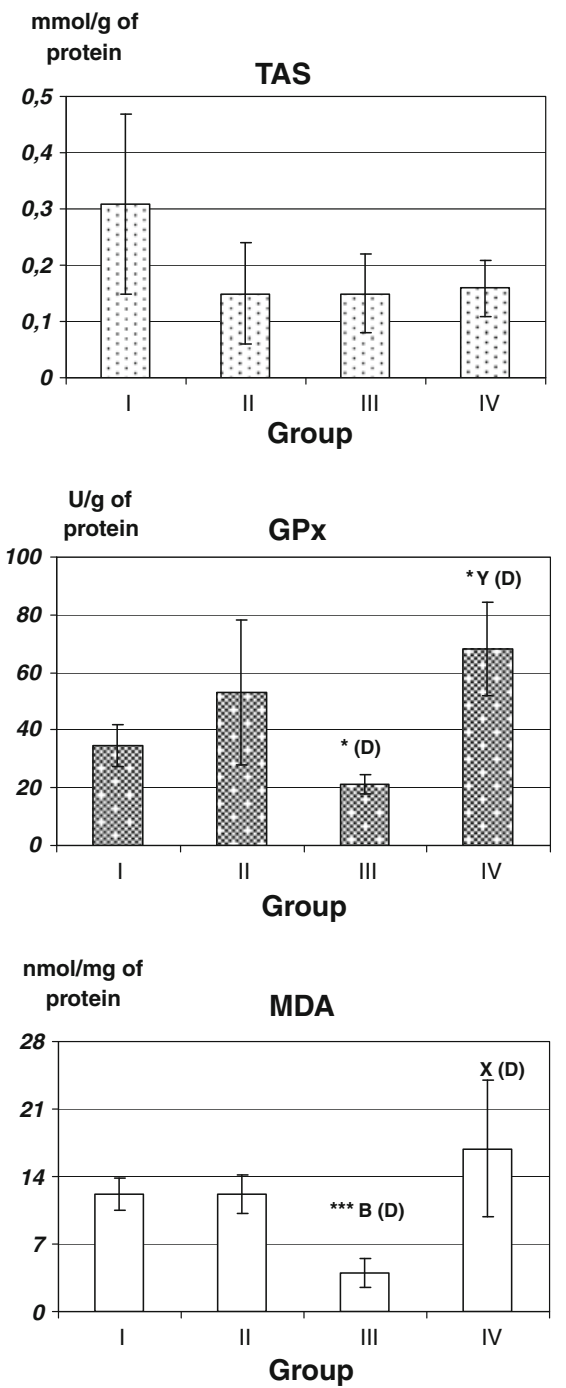
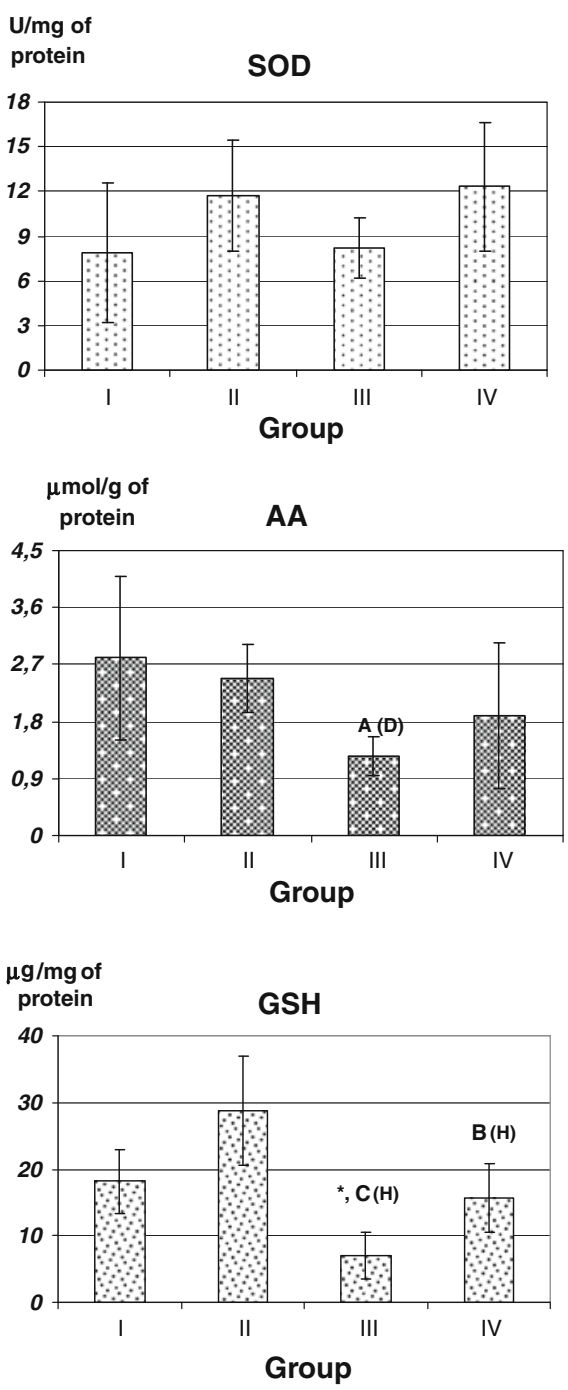

2010). Selenium given as sodium selenite increased GPx activity in cerebrum and cerebellum of suckling rats whose mother were administered methimazole during pregnancy and lactation. The same significant enhancement was observed in animals with no methimazole treatment. In the case of SOD increase was shown only in cerebellum of animals treated with methimazole, whereas in untreated selenium displayed no effect (Ben Amara et al. 2009).

As far as selenoorganic compounds are concerned the outcomes of the present study and others are divergent than what seems to be connected with different structures of the administered selenocompounds. Administration of DL-selenomethionine to mercury-exposed rat pups whose mothers were also subjected to the same treatment during pregnancy resulted in significant increase in hippocampal SOD activity (Su et al. 2008). Medeiros et al. (2012) found that selenoorganic compound of chain structure increased SOD activity only in the rat hippocampus, whereas GPx was reduced in all studied brain structures (cerebral cortex, hippocampus and cerebellum). In the present experiment the same result was obtained with regard to GPx in group III receiving chain selenocompound. Different results were obtained by Selamoglu Talas et al. In rats exposed to carcinogenic hydrocarbon, selenium, administered in form of two selenones, caused increase in both studied enzymes' activity (Selamoglu Talas et al. 2008). The differences between the referred findings and ours might result 
from the fact that in the present work the period of selenium administration was shorter. This assumption seems to be confirmed by observations reported by Ozkan et al. (2007) who found that in mice, exposed to cigarette smoke and selenium in form of L-selenomethionine, no significant changes of SOD and GPx were observed after 3 months, whereas after 5 months both enzymes were found to be increased. The significant decrease in GPx observed in the present study in group III could be caused by the comparatively great dose, whereas no changes or increase reported by Ozkan et al. may result from adaptive mechanism developed by organism during longer time of exposure.

Low-molecular antioxidants AA and GSH were not markedly influenced versus control in the present study, except for GSH in group III. Similarly, Agarval and Behari (2007) found that sodium selenite did not influence GSH concentration in brain of healthy and mercury-exposed rats. Sodium selenite showed ameliorating effect consisting in significant increase in GSH as well as in vitamin C concentration in cerebrum and cerebellum of rats undergoing exposure to chromium, whereas in non-exposed animals no significant effects were observed (Soudani et al. 2012), which confirms outcomes of the present study. Other scientists reported different outcomes but their experiments concerned selenium influence in animals additionally exposed to pathogenic factors. Naziroğlu et al. (2008) reported that in rats with pentylentetrazol-induced seizures earlier selenium administration resulted in both GSH and AA increase in cortex brain. As for GSH other studies were consistent with findings reported by Naziroğlu et al. In mercury-exposed rat pups whose mothers were also subjected to the same treatment during pregnancy DL-selenomethionine caused significant increase in hippocampal GSH concentration (Su et al. 2008). Increase in GSH concentration in rats exposed to carcinogenic hydrocarbon and receiving two selenooorganic compounds (selenones) was also observed by Selamoglu Talas et al. (2008). Selenium given as sodium selenite increased GSH concentration in cerebrum and cerebellum of suckling rats whose mothers were treated with methimazole during pregnancy and lactation. The similar significant enhancement was observed in animals with no methimazole treatment (Ben Amara et al. 2009).

In the present study MDA, a marker of lipid peroxidation, was not significantly influenced versus control, except for group III. The studies performed by other researchers are consistent with our results concerning inorganic selenite. In brain of healthy and mercury-exposed rats sodium selenite did not change MDA concentration (Agarval and Behari 2007). The similar effects were reported by Akil et al. $(2011 \mathrm{a}, \mathrm{b})$ who stated no effect of selenium supplementation (sodium selenite at two different doses: $6 \mathrm{mg} / \mathrm{kg} /$ day and $600 \mu \mathrm{g} / \mathrm{kg} /$ day) on MDA values in brain tissue and blood samples, respectively. Sodium selenite did not affect MDA concentration in cerebrum and cerebellum of suckling rats whose mothers were treated with methimazole during pregnancy and lactation. The same lack of influence was displayed in animals without methimazole administration (Ben Amara et al. 2009). In some cases of additional poisoning with heavy metals the outcomes of other authors were different. Sodium selenite given to rats did not influence distinctly brain TBARS (thiobarbituric acid-reactive substances) level in healthy animals, but in those exposed to aluminium significant decrease was observed (El-Demerdash 2004). Sodium selenite depressed TBARS in brain of suckling rats exposed to cadmium, whereas in nonexposed no significant influence was obtained (Lazarus et al. 2011). Similarly, sodium selenite exerted ameliorating effects on lipid peroxidation induced in rat cerebrum and cerebellum by chromium intoxication. MDA concentration was found to be significantly decreased. In non-exposed rats no influence was observed (Soudani et al. 2012).

The results concerning organic selenium are not consistent. It can be connected with the fact that administered compounds had different structures. Differences could also be the consequences of the additional pathogenic factors to which animals were exposed. Hippocampal MDA concentration in rat pups exposed to mercury and receiving selenium in form of DL-selenomethionine, whose mothers were also subjected to the same treatment during pregnancy, was significantly increased (Su et al. 2008). Administration of selenium, in form of two organic compounds (selenones), to rats exposed to carcinogenic hydrocarbon resulted in distinct decrease in MDA concentration (Selamoglu Talas et al. 2008). Organoselenium compound of chain structure did not influence in wellmarked way TBARS in rat hippocampus and cerebellum, whereas enhancement in the cerebral cortex was observed (Medeiros et al. 2012). Insignificant increase 
was observed in the present work in group IV, but the time of administration was considerably shorter (10 vs. 30 days).

Interestingly, in the present study the changes of GPx activity and GSH concentration were practically the same in groups II and III. In vitro study performed on cortical neurons of rat fetuses treated with organoselenium ring compound (ebselen) showed that concentration of GSH increased up to specific value of ebselen concentration. Further enhancement of ebselen concentration did not influence GSH concentration (Pawlas and Małecki 2007). Venardos et al. (2004) observed the similar dependence between liver GPx activity and selenium level in diet of experimental animals. It points that GSH, similarly as GPx activity, increases in selenium-dose-dependent way till a kind of "saturation" occurs. These observations are consistent, considering the fact that GSH is a substrate for GPx.

Selenium supplementation was found to show beneficial effect in cases of disturbances of nervous system. The study performed on rats revealed that selenium can slow down neurodegenerative processes (Zafar et al. 2003). Supplementation with micronutrients including selenium was revealed to improve symptoms of depression in older people (Gosney et al. 2008) and sodium selenite was suggested to be a promising compound for treatment of Alzheimer's disease (van Eersel et al. 2010). However, some authors reported opposite opinions (Loef et al.2011). Vinceti et al. (2010) hypothesized that dietary inorganic selenium may increase the risk of amyotrophic lateral sclerosis. Organic selenocompounds were studied in regard to their application in neurodegenerative diseases and the results were promising (Jauslin et al. 2002). Considering the possibility of the application of the studied compounds A and B as selenium-supplements, the outcomes of the present study show that although chain selenosemicarbazide significantly decreased lipid peroxidation level, it also caused impairment of antioxidant defence. 3-(2-chlorobenzoylamino)-2-(o-tolylimino-)-4-methyl-4-selenazoline of cyclic structure seems to be a more promising agent for future studies since it did not decrease elements of antioxidant barrier and increased GPx activity. As selenium is a constituent of GPx it could point that the bioavailability of selenazoline is better than that of selenosemicarbazide. Concluding, further studies with use of selenazoline appear to be advisable to evaluate its possible application as a selenium-supplement. As sex differences regarding selenium in vertebrates were reported (Raman et al. 2012) subsequent studies should include female rats.

Open Access This article is distributed under the terms of the Creative Commons Attribution License which permits any use, distribution, and reproduction in any medium, provided the original author(s) and the source are credited.

\section{References}

Agarval R, Behari JR (2007) Effect of selenium pre-treatment in chronic mercury intoxication in rats. Bull Environ Contam Toxicol 79:306-310

Akbaraly TN, Hininger-Favier I, Carrière I et al (2007) Plasma selenium over time and cognitive decline in the elderly. Epidemiology 18:52-58

Akil M, Bicer M, Menevse E, Baltaci AK, Mogulkoc R (2011a) Selenium supplementation prevents lipid peroxidation caused by arduous exercise in rat brain tissue. Bratisl Lek Listy 112:314-317

Akil M, Gurbuz U, Bicer M, Sivrikaya A, Mogulkoc R, Baltaci AK (2011b) Effect of selenium supplementation on lipid peroxidation, antioxidant enzymes, and lactate levels in rats immediately after acute swimming exercise. Biol Trace Elem Res 142:651-659

Ayaz M, Turan B (2006) Selenium prevents diabetes-induced alterations in $\left[\mathrm{Zn}^{2+}\right]_{\mathrm{i}}$ and metallothionein level of rat heart via restoration of cell redox cycle. Am J Physiol Heart Circ Physiol 290:H1071-H1080

Ben Amara I, Fetoui H, Guermazi F, Zeghal N (2009) Dietary selenium addition improves cerebrum and cerebellum impairments induced by methimazole in suckling rats. Int $\mathbf{J}$ Dev Neurosci 27:719-726

Bradford MM (1976) A rapid and sensitive method for the quantitation of microgram quantities of protein utilizing the principle of protein-dye binding. Anal Biochem 72:248-254

Burk RF, Norsworthy BK, Hill KE, Motley AK, Byrne DW (2006) Effects of chemical form of selenium on plasma biomarkers in a high-dose human supplementation trial. Cancer Epidemiol Biomarkers Prev 15:804-810

Chauhan A, Chauhan V, Brown WT, Cohen I (2004) Oxidative stress in autism: increased lipid peroxidation and reduced serum levels of ceruloplasmin and transferrin-the antioxidant proteins. Life Sci 75:2539-2549

Chen J, Berry MJ (2003) Selenium and selenoproteins in the brain and brain diseases. J Neurochem $86: 1-12$

Combs GF Jr (2005) Current evidence and research needs to support a health claim for selenium and cancer prevention. J Nutr 135:343-347

Cui XR, Takahashi K, Shimamura T, Koyanagi J, Komada F, Saito S (2008) Preparation of 1,8-di- $O$-alkylaloe-emodins and 15-amino-, 15-thiocyano-, and 15-selenocyanochrysophanol derivatives from aloe-emodin and studying their cytotoxic effects. Chem Pharm Bull 56:497-503

El-Demerdash FM (2004) Antioxidant effect of vitamin E and selenium on lipid peroxidation, enzyme activities and 
biochemical parameters in rats exposed to aluminium. J Trace Elem Med Biol 18:113-121

Farina M, Soares FA, Zeni G, Souza DO, Rocha JB (2004) Additive pro-oxidative effects of methylmercury and ebselen in liver from suckling rat pups. Toxicol Lett 146: 227-235

Feng J-F, Lu L, Zeng P et al (2012) Serum total oxidant/antioxidant status and trace element levels in breast cancer patients. Int J Clin Oncol 17:575-583

Ghodbane S, Amara S, Garrel C et al (2011) Selenium supplementation ameliorates static magnetic field-induced disorders in antioxidant status in rat tissues. Environ Toxicol Pharmacol 31:100-106

Ghosh P, Roy SS, Chakraborty P, Ghosh S, Bhattacharya S (2013) Effects of organoselenium compound 2-(5-selenocyanato-pentyl-benzo[de]isoquinoline 1,3-dione on cisplatin induced nephrotoxicity and genotoxicity: an investigation of the influence of the compound on oxidative stress and antioxidant enzyme system. Biometals 26:61-73

Glaser V, Nazari EM, Müller YM et al (2010) Effects of inorganic selenium administration in methylmercury-induced neurotoxicity in mouse cerebral cortex. Int J Dev Neurosci 28:631-637

Gosney MA, Hammond MF, Shenkin A, Allsup S (2008) Effect of micronutrient supplementation on mood in nursing home residents. Gerontology 54:292-299

Ha EJ, Smith AM (2009) Selenium-dependent glutathione peroxidase activity is increased in healthy post-menopausal women. Biol Trace Elem Res 131:90-95

Hawkes WC, Richter BD, Alkan Z et al (2008) Response of selenium status indicators to supplementation of healthy North American men with high-selenium yeast. Biol Trace Elem Res 122:107-121

Herrmann W, Schorr H, Purschwitz K, Rassoul F, Richter V (2001) Total homocysteine, vitamin $B_{12}$, and total antioxidant status in vegetarians. Clin Chem 47:1094-1101

Hoffmann PR, Jourdan-Le Saux C, Hoffmann FW et al (2007) A role for dietary selenium and selenoproteins in allergic airway inflammation. J Immunol 179:3258-3267

Horky P, Jancikova P, Sochor J et al (2012) Effect of organic and inorganic form of selenium on antioxidant status of breeding boars ejaculate revealed by electrochemistry. Int J Electrochem Sci 7:9643-9657

Ingen-Housz-Oro S, Blanchet-Bardon C, Vrillat M, Dubertret L (2004) Vitamin and trace metal levels in recessive dystrophic epidermolysis bullosa. J Eur Acad Dermatol Venereol 18:649-653

Ivancic J Jr, Weiss W (2001) Effect of dietary sulfur and selenium concentrations on selenium balance of lactating Holstein cows. J Dairy Sci 84:225-232

Jauslin ML, Wirth T, Meier T, Schoumacher F (2002) A cellular model for Friedreich Ataxia reveals small-molecule glutathione peroxidase mimetics as novel treatment strategy. Hum Mol Genet 11:3055-3063

Klarod K, Hongsprabhas P, Khampitak T et al (2011) Serum antioxidant levels and nutritional status in early and advanced stage lung cancer patients. Nutrition 27:1156-1160

Lazarus M, Orct T, Aladrović J, Ljubić BB, Jurasović J, Blanuša M (2011) Effect of selenium pre-treatment on antioxidative enzymes and lipid peroxidation in Cd-exposed suckling rats. Biol Trace Elem Res 142:611-622
Ledwożyw A, Michalak J, Stępień A, Kądziołka A (1986) The relationships between plasma triglycerides, cholesterol, total lipids and lipid peroxidation products during human atherosclerosis. Clin Chim Acta 155:275-284

Liu JG, Zhao HJ, Liu YJ, Wang XL (2006) Effect of seleniumenriched malt on hepatocarcinogenesis, paraneoplastic syndrome and the hormones regulating blood glucose in rats treated by diethylnitrosamine. Life Sci 78:2315-2321

Loef M, Schrauzer GN, Walach H (2011) Selenium and Alzheimer's disease: a systematic review. J Alzheimers Dis 26:81-104

Ma Y, Wu M, Li D et al (2012) Embryonic developmental toxicity of selenite in zebrafish (Danio rerio) and prevention with folic acid. Food Chem Toxicol 50:2854-2863

Mariani E, Polidori MC, Cherubini A, Mecocci P (2005) Oxidative stress in brain aging, neurodegenerative and vascular diseases: an overview. J Chromatogr B Analyt Technol Biomed Life Sci 827:65-75

Medeiros MC, Mello A, Gemelli T et al (2012) Effect of chronic administration of the vinyl chalcogenide 3-methyl-1-phenyl-2-(phenylseleno)oct-2-en-1-one on oxidative stress in different brain areas of rats. Neurochem Res 37:928-934

Musik I, Kozioł-Montewka M, Toś-Luty S, Donica H, Pasternak K, Wawrzycki S (2002) Comparison of selenium distribution in mice organs after the supplementation with inorganic and organic selenium compound selenosemicarbazide. Ann Univ Mariae Curie Sklodowska Med $57: 15-22$

Musik I, Kiełczykowska M, Hordyjewska A, Pasternak K (2009) Influence of different forms of selenium supplementation on superoxide dismutase activity and total antioxidant status in rats. Ann Univ Mariae Curie Sklodowska Pharm 22:95-101

Naziroğlu M, Kutluhan S, Yilmaz M (2008) Selenium and topiramate modulates brain microsomal oxidative stress values, $\mathrm{Ca}^{2+}$-ATPase activity, and EEG records in pentylentetrazol-induced seizures in rats. $\mathrm{J}$ Membr Biol 225:39-49

Okuonghae PO, Aberare LO, Mukoro N et al (2011) Total antioxidant status of zinc, manganese, copper and selenium levels in rats exposed to premium motor spirit fumes. N Am J Med Sci 3:234-237

Ozkan A, Fiskin K, Ayhan AG (2007) Effect of vitamin E and selenium on antioxidant enzymes in brain, kidney and liver of cigarette smoke-exposed mice. Biologia 62:360-364

Pagmantidis V, Melon C, van Schothorst EM, Keijer J, Hesketh JE (2008) Supplementation of healthy volunteers with nutritionally relevant amounts of selenium increases the expression of lymphocyte protein biosynthesis genes. Am J Clin Nutr 87:181-189

Pavlović Z, Miletić I, Jokić Ž, Pavlovski Z, Škrbić Z, Šobajić S (2010) The effect of level and source of dietary selenium supplementation on eggshell quality. Biol Trace Elem Res 133:197-202

Pawlas N, Małecki A (2007) Effects of ebselen on glutathione level in neurons exposed to arachidonic acid and 4-hydroxynonenal during simulated ischemia in vitro. Pharmacol Rep 59:708-714

Raman AV, Pitts MW, Seyedali A et al (2012) Absence of selenoprotein $\mathrm{P}$ but not selenocysteine lyase results in severe neurological dysfunction. Genes Brain Behav 11:601-613 
Rayman MP (2000) The importance of selenium to human health. Lancet 356:233-241

Řezanka T, Sigler K (2008) Biologically active compounds of semi-metals. Phytochemistry 69:585-606

Rutkowski M, Grzegorczyk K (1998) Colorimetric determination of vitamin $\mathrm{C}$ concentration in blood plasma with phosphotungstic reagent-a modification of Kyaw method. Diagn Lab 34:511-520 (in Polish)

Savory LA, Kerr CJ, Whiting P, Finer N, McEneny J, Ashton T (2012) Selenium supplementation and exercise: effect on oxidant stress in overweight adults. Obesity (Silver Spring) 20:794-801

Schnabel R, Lubos E, Messow CM (2008) Selenium supplementation improves antioxidant capacity in vitro and in vivo in patients with coronary artery disease The SElenium Therapy in Coronary Artery disease Patients (SETCAP) Study. Am Heart J 156:1201.e1-1201.e11

Selamoglu Talas Z, Ozdemir I, Yilmaz I, Gok Y, Orun I (2008) The investigation of the antioxidative properties of the novel synthetic organoselenium compounds in some rat tissues. Exp Biol Med 233:575-579

Selamoglu Talas Z, Yilmaz I, Ozdemir I, Ates B, Gok Y, Cetinkaya B (2009) Role of synthesized organoselenium compounds on protection of rat erythrocytes from DMBAinduced oxidative stress. Biol Trace Elem Res 128:167-175

Shi H, Liu S, Miyake M, Liu KJ (2006) Ebselen induced C6 glioma cell death in oxygen and glucose deprivation. Chem Res Toxicol 19:655-660

Skelton JA, Havens PL, Werlin SL (2006) Nutrient deficiencies in tube-fed children. Clin Pediatr (Phila) 45:37-41

Sopjani M, Föller M, Gulbins E, Lang F (2008) Suicidal death of erythrocytes due to selenium compounds. Cell Physiol Biochem 22:387-394

Soudani N, Troudi A, Amara IB, Bouaziz H, Boudawara T, Zeghal N (2012) Ameliorating effect of selenium on chromium (VI)-induced oxidative damage in the brain of adult rats. J Physiol Biochem 68:397-409

Steibrenner H, Sies H (2013) Selenium homeostasis and antioxidant selenoproteins in brain: implications for disorders in the central nervous system. Arch Biochem Biophys. doi: 10.1016/j.abb.2013.02.021

Su L, Wang M, Yin ST et al (2008) The interaction of selenium and mercury in the accumulations and oxidative stress of rat tissues. Ecotoxicol Environ Saf 70:483-489

Uezono Y, Toyohira Y, Yanagihara N, Wada A, Taniyama K (2006) Inhibition by selenium compounds of catecholamine secretion due to inhibition of $\mathrm{Ca}^{2+}$ influx in cultured bovine adrenal chromaffin cells. J Pharmacol Sci 101:223-229

van Eersel J, Ke YD, Liu X et al (2010) Sodium selenate mitigates tau pathology, neurodegeneration, and functional deficits in Alzheimer's disease models. Proc Natl Acad Sci USA 107:13888-13893

Venardos K, Harrison G, Headrick J, Perkins A (2004) Effects of dietary selenium on glutathione peroxidase and thioredoxin reductase activity and recovery from cardiac ischemia-reperfusion. J Trace Elem Med Biol 18:81-88

Vinceti M, Bonvicini F, Rothman KJ, Vescovi L, Wang F (2010) The relation between amyotrophic lateral sclerosis and inorganic selenium in drinking water: a populationbased case-control study. Environ Health 9:77-84

Xia R, Ganther HE, Egge A, Abramson JJ (2004) Selenium compounds modulate the calcium release channel/ryanodine receptor of rabbit skeletal muscle by oxidizing functional thiols. Biochem Pharmacol 67:2071-2079

Yan J, Zheng Y, Min Z, Ning Q, Lu S (2013) Selenium effect on selenoprotein transcriptome in chondrocytes. Biometals. doi:10.1007/s10534-013-9610-x

Zafar KS, Siddiqui A, Sayeed I, Ahmad M, Salim S, Islam F (2003) Dose-dependent protective effect of selenium in rat model of Parkinson's disease: neurobehavioral and neurochemical evidences. J Neurochem 84:438-446

Zhang Z, Zhang J, Gao Y et al (2013) Effect of oxygen free radicals and nitric oxide on apoptosis of immune organ induced by selenium deficiency in chickens. Biometals. doi:10.1007/s10534-013-9612-8 